Escuela de Historia

Centro de Investigaciones Históricas de América Central

Postgrado Centroamericano en Historia

Número especial de Diálogos. Revista electrónica de Historia

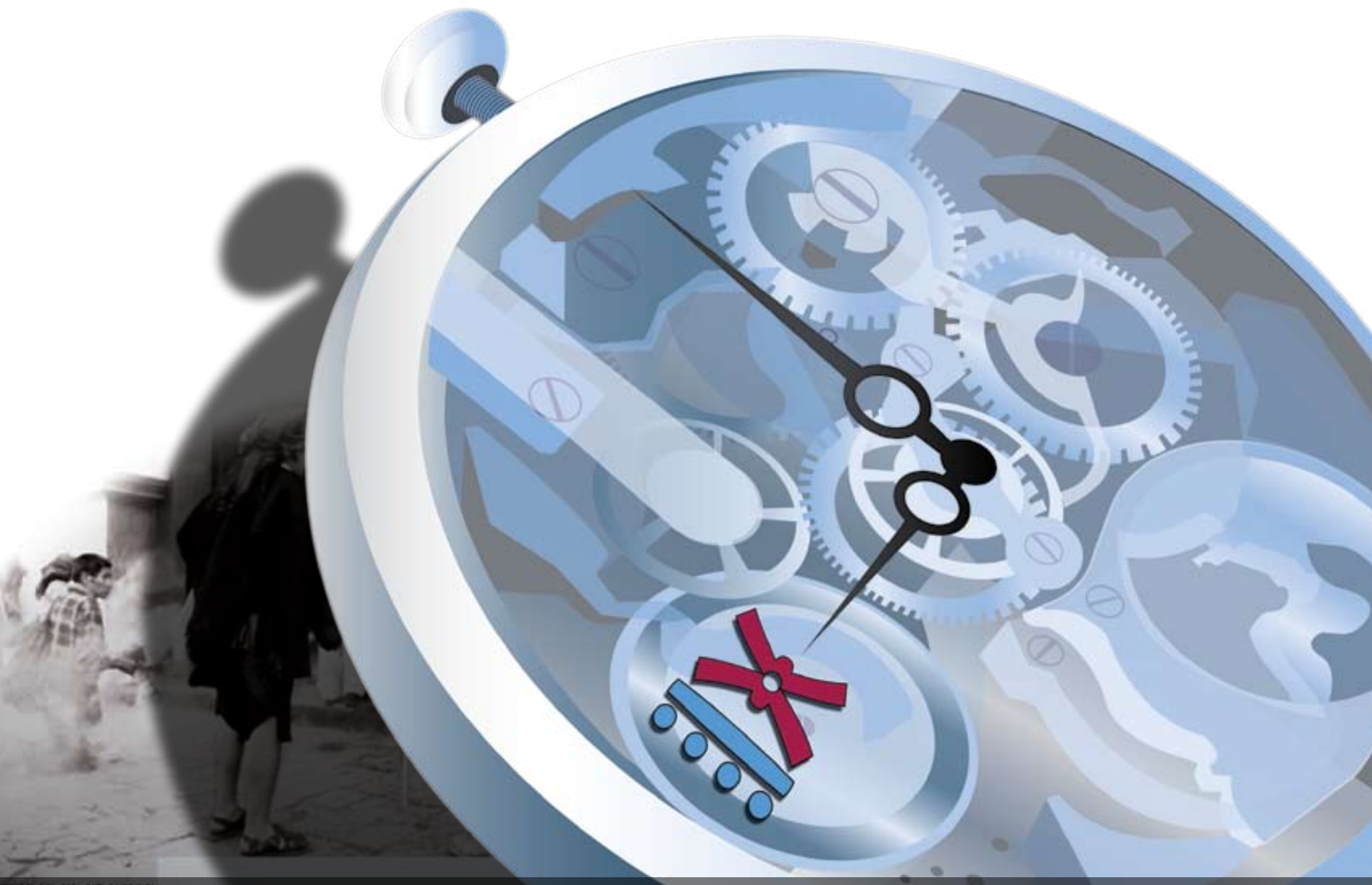

O $9^{\circ}$ C O N G R E S O 2. CENTROAMERICANO DE H I S T O I A

ISSN 1409-469X

Fecha de recepción: 15 de mayo 2008 Fecha de aceptación: 30 de mayo 2008

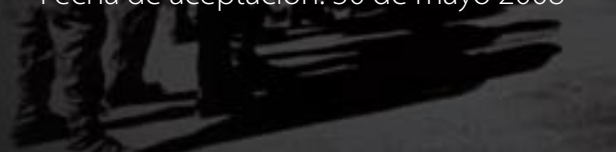

\section{LA ESCLAVITUD EN CARTAGO 1750-1775}

Miembros del Consejo Editorial:

Dr. Ronny Viales, Dr. Juan José Marín

Editores Técnicos:

Allan Fonseca, Andrés Cruz, Gabriela Soto

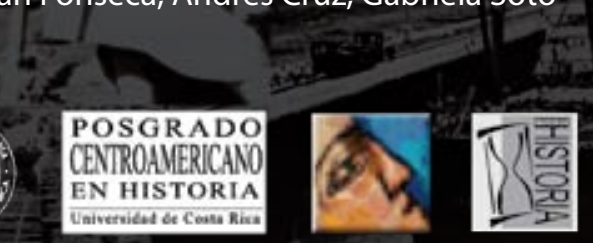


Indexaciones: Repositorio de Revistas UCR, DIALNET, Latindex, REDALYC Directorio y recolector de recursos digitales del Ministerio de Cultura de España, Directory of Open Access Journals. Diálogos Revista Electrónica de Historia ISSN 1409- 469X. Número especial 2008. Dirección web: http://historia.fcs.ucr.ac.cr/dialogos.htm

\section{LA ESCLAVITUD EN CARTAGO 1750-1775}

\section{Dr. José R. Corrales}

El profesor José R. Corrales, posee un doctorado en Historia de Puerto Rico y el Caribe, es Catedrático y ocupa actualmente el cargo de Director del

Departamento de Humanidades de la Facultad de Estudios Generales y Presidente de la Junta de Disciplina del Recinto de Río Piedras de la Universidad de Puerto

Rico.Su correo electrónico es jrcorrales@uprrp.edu 


\title{
Dedicatoria:
}

\author{
A mis profesores de Historia y Geografía \\ que ya no están con nosotros, y que \\ dejaron una huella inmensa en nuestras \\ vidas como aprendiz de Historiador.
}

\section{Introducción}

El historiador Oscar Aguilar Bulgarelli ha afirmado que Cartago ha sido la provincia más estudiada en Costa Rica por los historiadores y que esto se debe probablemente a que fue la ciudad más importante durante la época colonial y esto ha permitido que se descuide el estudio de otras áreas del País. Los registros de nacimiento, matrimonios y defunciones de la población esclava en los archivos eclesiásticos son una excelente fuente de información.

Esta investigación de la esclavitud en Cartago de 1750 a 1775, surgió como producto de un curso doctoral en 1991 en el Departamento de Historia de la Universidad de Puerto Rico, Recinto de Río Piedras. La temática del curso era sobre la esclavitud en América Latina y el Caribe y esto me motivó a realizar esta investigación. El curso consistió en un mes intenso de clases y otro de investigación. Por lo tanto, me trasladé a Costa Rica y visité por un mes el Archivo Nacional y las bibliotecas de las Universidades de Costa Rica y la Nacional.

Escogí la primera parte del siglo XVIII por ser abundante la información, además fue un siglo muy importante para la historia económica y social de Costa Rica por la importancia de la producción de cacao y tabaco. El tema de esclavitud en el siglo XVI es escasa, para los siglos XVII al XIX es abundante y dicha documentación se encuentra en muy buen estado de conservación e inclusive se podría hacer un estudio regional centroamericano sobre el tema de la esclavitud.

SicomparamoslaimportanciaquetuvolaesclavitudenCosta Ricaconotrasregionescentroamericanas y caribeñas, podríamos concluir que su importancia para Costa Rica fue determinante debido a que la producción de cacao no se hubiese dado en esa escala, sin la mano de obra esclava. Por lo tanto, esto permitió a la elite social, política y económica de Cartago acumular capital y bienes para el impulso de la producción cafetalera y otras industrias en el siglo XIX. 


\section{La provincia de Costa Rica}

Cartago fue la capital de la provincia de Costa Rica durante la época colonial. Desde 1563, el conquistador Juan Vázquez de Coronado trazó los planos de lo que sería Cartago. La economía de Costa Rica se orientó en tres direcciones: en el monopolio comercial, el sistema tributario, y en su ubicación geográfica privilegiada con respecto a su cercanía al mar. La marginalidad con respecto a la Capitanía General ubicada en Guatemala era muy evidente. Costa Rica se caracterizó por tener poca población, lo cual dificultó su desarrollo y el colono tuvo que adquirir mano de obra esclava para ayudarse en sus haciendas. El cacao fue el producto que le dio el impulso necesario al hacendado radicado en Cartago para comprar por la vía legal o ilegal dicha mano de obra. Desde luego, éste no fue el único uso del esclavo; una buena cantidad de ellos se ocuparon en trabajos domésticos y otros en las poblaciones del interior de la provincia.

Obtener esclavos mediante compra legal era muy difícil; pero esta situación mejoró gracias al interés de los ingleses, que desde Jamaica fomentaron sus actividades del tráfico de esclavos en el Caribe. Pese a esto, Costa Rica quedó bastante marginada de la trata negrera durante el siglo XVIII. El decomiso de uno o varios esclavos sufría todo un complejo proceso que, por lo general, se cumplía en todas sus partes, o sea:

1. Se presentaba el esclavo, se hacía una declaración y se evaluaba.

2. Se hacía una investigación exhaustiva sobre la forma de ingreso a la provincia.

3. Se sentenciaba, si era el caso.

4. Se realizaba el remate, mediante el pago previo a su publicación por un pregón.

5. Y se le adjudicaba a un nuevo y legal propietario.

Para el pregón, se contrataban los servicios de un indio o mestizo, quien por nueve veces gritaba por las calles de Cartago las condiciones en que se pensaba rematar el esclavo y al momento del remate decía: “a la una, a las dos, a la tercera, que es buena, y verdadera que buena, que buena, que buena prole haga”. ${ }^{1}$

La escasez de mano de obra indígena y la ausencia de metales preciosos, hicieron de Costa Rica una región poco atractiva para los inmigrantes españoles. Por ende, su situación en el extremo más apartado de la Audiencia de Guatemala, determinó que fuese una zona bastante olvidada

1 M. Brenes Castillo, Matina: Bastión del contrabando en Costa Rica (San José, Costa Rica: Tesis de Licenciatura en Historia. Universidad de Costa Rica, 1976), 59. 
por las autoridades coloniales asentadas en la capital de la Audiencia, pero no lo suficiente como para permitirle a Costa Rica disgregarse de ésta y unirse a la Audiencia de Panamá, con la cual mantenía relaciones más estrechas por razones de distancia y de comercio, pese a la oposición de Guatemala a esta unión con Panamá. Todo esto se convirtió en un obstáculo más para el desarrollo de la provincia. ${ }^{2}$

La unión de estos factores condicionó la formación de una sociedad escasamente desarrollada y poco poblada. La mayoría de los habitantes se vieron obligados a vivir en un régimen de subsistencia. Por estas razones, la generalidad de los pobladores se mantenían dispersos en los campos que circundaban los escasos y diminutos centros de población. Incluso, Cartago para 1719 contaba a penas con 70 casas de adobe y tejas, y sus moradores pasaban la mayor parte de la semana en los campos cercanos, labrando sus sementeras para poder subsistir. ${ }^{3}$

\section{Trasfondo histórico de la esclavitud en Costa Rica}

Se dice que treinta negros acompañaron a Vasco Núñez de Balboa al descubrir éste el Océano Pacífico; algunos acompañaron a Gil González en 1522-1523 en su recorrido por las costas del Pacífico de Costa Rica y Nicaragua; nueve acompañaron a Hernán Sánchez de Badajoz en 1540 en su expedición a la "costa rica”; Cavallón al entrar a colonizar el Valle Central, vino con noventa "españoles y negros". ${ }^{4}$

Es evidente por las breves referencias dadas, que numéricamente los esclavos significaron en estos momentos, muy pocos. Posteriormente, en el año 1569, Monseñor Thiel dijo que la población de Costa Rica censada sumaba un total de 17,479 individuos que se distribuían así: 5

Indios

Mulatos, Zambos y Pardos
17.166

170

2 Carlos Solórzano Fonseca, Comercio exterior de la provincia de Costa Rica, 1690-1760 (San José, Costa Rica: Tesis de Licenciatura en Historia. Universidad de Costa Rica, 1977), 6.

3 Solórzano, 7.

4 Carlos Meléndez y Quince Duncan, El negro en Costa Rica, (San José, Costa Rica: Editorial Costa Rica, 1972), 22.

5 Bernardo Thiel, “La población de Costa Rica en el siglo XIX”, Revista de Costa Rica (Costa Rica), I, (1902):8 
Españoles

Negros

Total
113

30

17,479

Si observamos los números tenemos que la cantidad de negros era pequeña, pero es significativo el número de mulatos, zambos y pardos. Tampoco debemos olvidar que Thiel no visitó pueblo por pueblo, y que esos esclavos eran los legalmente admitidos o que por lo menos estaban registrados.

Además, podemos ver en el siguiente cuadro, el aumento de la población negra, mulata, zamba y parda desde 1569 a $1801 .^{6}$ M U L A T O S ,

$\begin{array}{lcccc}\text { AÑO } & \text { Z A M B O S NEGROS } & \text { POBLACIÓN TOTAL } \\ & \text { PARDOS } & & \\ 1569 & 170 & 30 & 17,479 \\ 1611 & 250 & 25 & 15,538 \\ 1700 & 1291 & 154 & 19,293 \\ 1720 & 2193 & 168 & 19,427 \\ 1741 & 3063 & 200 & 24,126 \\ 1751 & 2987 & 62 & 24,022 \\ 1778 & 6053 & 94 & 34,212 \\ 1801 & 8925 & 30 & 52,591\end{array}$

En las cifras anteriores podemos notar que la población mulata, zamba y parda estaba creciendo considerablemente, el número de negros fue poco, de ahí que la mayor parte de la actividad esclavista recayera en los mulatos.

El historiador Aguilar Bulgarelli sostiene que no debemos confiar en los datos de Monseñor Thiel debido a que entre 1700 Y 1720, únicamente se aumenta en 14 individuos, sin embargo, en 1701 se introdujeron 41 negros de contrabando. Fray Francisco de San José en 1702 compró a los tripulantes de una balandra 14 individuos, en 1710 a raíz del encallamiento de dos barcos

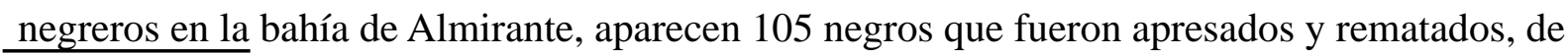
6 Thiel,8. 
los cuales 27 pasaron a manos del gobernador. En 1719, hay un largo proceso contra varias personas por comercio ilícito realizado en Matina, fundamentalmente de esclavos. ${ }^{7}$ Por lo tanto, si comparamos los datos de Bulgarelli con los de Monseñor Thiel tenemos una diferencia evidente.

Por otro lado, el historiador Carlos Meléndez afirmó que "el monto mayor de esclavos no legítimamente introducidos resultó ser en 1721, de cuarenta y nueve, y no todos entrados por contrabando". ${ }^{8}$ Esta cita se refiere indudablemente al proceso que mencionamos que se realizó en 1719 por el gobernador Diego de la Haya, y que culmina en el año 1721. Sin embargo, como ya dijimos antes, el comercio que se realizó en 1710, sobre una cifra de 105 esclavos, supera la afirmación que comentamos, pues aunque también hubo un largo proceso sobre estos hechos, lo cierto es que para 1714 esos esclavos se habían incorporado a la población negra de Costa Rica. $^{9}$

En Costa Rica las castas dominantes en el siglo XVIII fueron la Conga y Mina, pero en el siglo XVII predominaron la Conga y Angola, ambos del grupo Bantú, aunque dominando la Conga en proporción de dos por uno. Para el siglo XVIII se fortalece la inmigración de la casta Mina. ${ }^{10}$ A partir del Tratado de Utrech de 1713, Inglaterra hereda la concesión del comercio de esclavos por 30 años, hasta 1739, año en que entra en guerra con España y los británicos pierden la concesión. Sin embargo, en 1748 se les renueva el permiso por dos años, después se deja definitivamente sin efecto. Este periodo de tráfico esclavista inglés tuvo grandes repercusiones en Costa Rica, no solo por la trata de negros desde mucho antes de constituirse en concesionarios de la Corona Española, sino que también ejerciendo el contrabando entre los colonos, el comercio con ellos era importante por las diversas mercancías que se introducían de Jamaica, especialmente por Matina. ${ }^{11}$

\section{El comercio esclavo}

Por ahora, nos interesa referirnos a algunas aseveraciones que se han dado tradicionalmente sobre las condiciones sociales y económicas de Costa Rica. En síntesis, se ha afirmado que durante la colonia, Costa Rica fue una provincia sumida en la más profunda pobreza, lo que $7 \quad$ Aguilar, 4.

8 Meléndez, 24.

9 Aguilar, 5.

10 Meléndez, 18.

11 Brenes, 61. 
originó la necesidad de que todos sus habitantes tuvieran que dedicarse plenamente al cultivo de la tierra para no morir de hambre y que esto originó una igualdad social en la que no hubo "castas ni esclavitud”, ${ }^{12}$ y que dio origen a la llamada "democracia rural” o "democracia social”, a la cual el historiador Aguilar Bulgarelli le llama “democracia romántica”, pues no es más que el producto de una actitud sentimental y poco científica. ${ }^{13}$

Indudablemente, en Costa Rica hubo diferencias de clase durante el período colonial, tal vez no en la forma tan marcada como en otras latitudes del continente, pero las hubo. Esa diferencia social, fue fundamentalmente basada en el aspecto económico. En Cartago existió un reducido sector de la población con una importante fortuna, que los diferenciaba del resto de la población. Esa riqueza había sido traída del exterior, o bien se había consolidado y acrecentado con la explotación del cacao. Un ejemplo de ello, se dio en la zona de Matina, en el desempeño de funciones de gobierno de la provincia y, con el comercio de mulas con Panamá y con Cartagena de Indias.

Estos temas todavía no se han estudiado con profundidad, incluso habría que añadir el comercio ilícito que pudo ser un factor importante en el fortalecimiento de esas fortunas. ${ }^{14}$ Ese sector enriquecido fue el que propició la esclavitud, bien fuera para el servicio doméstico, o bien para el trabajo agrícola en las plantaciones de cacao de Matina. Recordemos que estos hacendados, especialmente los cartagineses, se trasladaban dos veces por año a sus plantaciones, para la época de la cosecha. Pero aún más, los propios testamentos nos indican la existencia de importantes cantidades de dinero invertidas en esclavos. Una persona que tenía en su poder más de 10 ó 12 esclavos en la época colonial era poseedora de un capital importante. Hemos ligado dos actividades importantes a la esclavista con la ocupación de cargos políticos, religiosos o militares. Entre ellos el Presbítero José F. Casasola y Córdova, el Teniente Luis Diez Navarro, el Alférez Cayetano Pacheco, el Capitán Cristóbal Ignacio De Soria, el Obispo Mateo José de Nava, el Notario Apostólico Antonio de la Fuente, el Licenciado Juan de la Haya, el Corregidor Juan Garau, (Noble) y Francisco Leal. ${ }^{15}$

Las necesidades de mano de obra para el cultivo del cacao eran relativamente escasas, según el historiador Carlos Roses una hacienda de cacao podía ser explotada con sólo dos esclavos. 12 Carlos Monge Alfaro, Historia de Costa Rica, (San José, Costa Rica: Imprenta Trejos, 1966), 137-138.

13 Aguilar, 9.

14 Aguilar, 10.

15 ANCR, Protocolos de Cartago. 1750-1775. 
Esta característica explicaría, en parte, el hecho de que fuese el cacao el primer producto de importancia con el que los colonos de Cartago intentaron unirse al comercio colonial teniendo en cuenta la imposibilidad local de una gran disponibilidad de mano de obra. ${ }^{16}$

A pesar de lo poco exigente que fue el cultivo del cacao en cuanto a la mano de obra, en el desarrollo del cultivo de este fruto en Costa Rica, el problema de obtención de mano de obra, fue uno de los factores que más perjudicaron al cultivo. La escasez de mano de obra se debió a diferentes factores. Costa Rica aún en la época precolombina no tuvo una gran densidad poblacional, la poca que hubo en las zonas de asentamiento español fue rápidamente utilizada y diezmada por los nuevos colonos, a ello contribuyó la peste de 1690 que afectó en especial a los indígenas del Valle Central.

Las diversas formas de comercio o transacciones de esclavos se dieron bajo la normativa de: hipotecas, donaciones, venta, carta dote, herencia y liberación. A partir del siglo XVII, las transacciones aparecen en un número bastante considerable para el medio costarricense, e incluso tenemos referencias de que se efectuaron transacciones todos los años a partir de 1650 hasta la primera década del siglo XIX. La venta y la liberación fueron los dos elementos más importantes en el intercambio y el comercio esclavo. Es difícil encontrar transacciones de venta que se refieran a más de tres esclavos en una sola transacción, predominando casi en su totalidad la venta de dos o de un individuo. Por otra parte, es frecuente encontrar testamentos en que el testador aparece como dueño de cinco, siete, diez y hasta doce esclavos. Algunos ejemplos son: ${ }^{17}$

\section{Fecha del testamento}

26 de abril de 1753

15 de diciembre de 1753

22 de agosto de 1759

22 de septiembre de 1762

\section{testador}

C.I. de Soria

J.J. de Cuende

Catalina de Siles

T. de Soto

\section{número de esclavos}

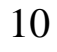

10

9

12

A pesar de que no abarcan un gran número las herencias en que se declararon importantes cantidades de esclavos, éstas fueron importantes. Con relación a la liberación de esclavos, bien sea por gracia o por compra de su propia libertad, la referencia más antigua de este tema que

16 Carlos Roses Albarado, El cacao en la economía colonial (San José, Costa Rica: Tesis de Licenciatura en Historia. Universidad de Costa Rica, 1977), 19.

17 Archivo Nacional de Costa Rica, (ANCR), Protocolos de Cartago. Números 943, 948,950, Legajos VII, Exps. 5, 10 y 12. 
hemos logrado encontrar es de 1648 en que Diego de Peñaranda, por voluntad testamentaria, dispuso que su esclavo Diego de Sojo, mulato, deseaba libertarse, y se le daría la carta requerida, una vez cancelara la suma de quinientos pesos.

En ese mismo año, se produce la liberación del mulato Hernando López, por voluntad expresada en el testamento de Francisca de Sojo y Peñaranda, de ahí que no es como se ha afirmado, que las liberaciones se producen a partir de $1677 .{ }^{18}$

Es importante recalcar, que en ningún momento encontramos la liberación masiva de esclavos, ni un número considerable, salvo el caso excepcional de finales del siglo XVIII en que se liberan los esclavos para entrar en negociaciones de arriendo con los cultivadores de cacao, ya en decadencia, especialmente a través del arriendo de las plantaciones por tiempo limitado. A continuación citamos algunos ejemplos de estas libertades compradas. ${ }^{19}$

Todos estos esclavos compraron su libertad trabajando en las plantaciones de cacao, generalmente tardaban entre dos y tres años para pagar su libertad. Solamente, Catarina de Siles le pidió a su esclava que le hiciera algunas misas. Un aspecto importante que debemos mencionar en el comercio esclavo, es el número de hombres y mujeres que aparecen en las referencias. En la serie de años estudiados, podemos decir que el total de esclavos vendidos, heredados, etc., fue de 131 varones y 127 mujeres de un total de 306 esclavos; desconocemos el sexo de 48 de ellos.

\section{PROPIETARIO}

José M. de Guzmán José M. de. Guzmán

Catarina de Siles

Josefa Guerrero

María Mosés

José F. Cháves

María de Arburdo

José F. Reyes

José A. Oriamuno

Manuela de Favoleta

Félix García

Manuela G. Sancho

Josefa del Corral

Josefa del Corral

\section{ESCLAVO}

Ramón Paveda

Ramón Paveda, María. del Rosario Juan

Juan Agustín

María Josefa

Juan Cayetano

María. de la Cruz Manuela de la T.

Matías Favoleta

Juan M. Fallas

Paula de las D.

Juana María

José Domingo
EDAD

Hijo

$18 \quad$ Aguilar, 7.

19 ANCR, Protocolos de Cartago. Números 940-963, Legajos VII.

$\begin{array}{ll}\text { AÑO } & \text { MONTO } \\ & \text { (PESOS) } \\ 1750 & 300 \\ 1752 & 50 \\ 1759 & \text { Misas } \\ 1760 & 300 \\ 1762 & 300 \\ 1764 & 200 \\ 1766 & - \\ 1768 & 200 \\ 1770 & - \\ 1771 & 200 \\ 1771 & 133 \\ 1772 & 200 \\ 1774 & - \\ 1774 & 120\end{array}$


Esto indica que no hubo gran diferencia numérica entre un sexo y otro.

En la década de 1750 a 1760 existió una diferencia importante, ya que aparecen 27 varones y 17 mujeres, lo que probablemente se deba a la importancia que adquirió la actividad cacaotera y tabacalera en Matina y en el Valle Central, la que fue decayendo conforme avanzó el siglo XVIII, especialmente en su segunda mitad. Por otra parte, la cantidad de esclavas que aparece puede ser debido a su importancia en el trabajo doméstico, lo que nos indicaría la existencia de una clase económica fuerte en Cartago. ${ }^{20}$

Es importante indicar que el valor de un esclavo era determinado por su edad, sexo, condición de salud y otros factores como el carácter y procedencia del esclavo es decir, si había nacido en la familia o había sido comprado. Un esclavo de cerca de 20 años era el más cotizado. En Costa Rica se le podía comprar por cerca de 300 pesos moneda de cacao, lo que equivalía a 150 pesos de plata o sea, la mitad. La suma mayor no sobrepasó los 500 pesos, por algún esclavo calificado. Un niño mulato esclavo de un mes, podía ser comprado por 50 pesos en $1752 .{ }^{21}$ Una mujer negra de 55 años, fue vendida por 150 pesos. En 1820 un mulato esclavo de cinco años, fue vendido por 100 pesos. $^{22}$

Una apreciación general acerca de los precios de los esclavos, llevó al historiador Carlos Meléndez a pensar que eran mucho más baratos los esclavos en el siglo XVIII que en el siglo XVII. En 1629 un negro criollo de cerca de 35 años fue vendido en cerca de 500 pesos de plata y poco más tarde un mulato de 16 años costó 350 pesos. En el siguiente siglo un negro de 35 años fue vendido en 350 pesos de cacao, o sea, 165 de plata y otro mulato de 16 costó 300 pesos. Esto obedecía sin lugar a dudas, a una mayor y mejor organización del mercado negrero por los ingleses, que abarató este tipo de “mercancías”. ${ }^{23}$

Un esclavo de 350 pesos representaba el valor de 100 cabezas de ganado vacuno. Es posible que el trabajo más fuerte lo realizaran los indios a los que se les podía contratar por unos pocos pesos. Según Monseñor Thiel en el siglo XVI, Costa Rica estaba habitado por 27,000 indios (96\% de la población) y sólo por un 2\% de negros y un 2\% de españoles. En 1777, habían 3,246 negros y mulatos, distribuidos de la siguiente manera: San José con 764, Ujarrás con 220, Esparta con 474 y Cartago con $1,788 .{ }^{24}$ De lo cual, se infiere, que la población indígena estaba

20 ANCR, Protocolos de Cartago. Números 940-948, Legajos VII.

21 ANCR, Protocolos de Cartago. Número 942, Legajo VII. Exp.4.

22 Meléndez, 30.

23 Meléndez, 30.

24 Wilburg Jiménez Castro, Migraciones internas en Costa Rica, (Washington, D.C.: Unión Panamericana, 1956$), 17$. 
disminuyendo. A la inversa, notamos un incremento considerable de la población negra. Ahora bien, ¿qué importancia representó para Costa Rica la esclavitud? Por las actividades que realizaron los esclavos, se dedicaron a tres actividades principales en las que solían ocuparse a dichos esclavos: en las ciudades, se les empleó en oficios domésticos y en labores artesanales y en las áreas rurales como trabajadores en el campo. ${ }^{25}$ Su valor estaba determinado por las habilidades, condiciones de salud y destrezas.

\section{Linajes y mezcla racial}

Costa Rica, durante la época colonial estuvo básicamente habitada por tres etnias: la blanca, la india y la negra. La mezcla de éstas produjo otros tipos raciales: los mestizos (español con india), mulatos (español con negra) y zambos (indio con negra).

Pudimos observar que los apellidos se repiten de una generación a otra: Alvarado, Bonilla, Echevarria, Guzmán, Casasola, López de la Flor, De la Fuente, López del Corral, García, Ibarra, etc. ${ }^{26}$ Algunos apellidos se pierden por falta de descendencia, pero las fortunas quedaban en manos de la familia y de la Iglesia, a través de las cofradías y de las capellanías. Un problema en este estudio de las familias, es el hecho de que las personas podían optar por el apellido del padre o de la madre; en otras ocasiones los apellidos podían variar como es el caso de Teruel por Terruel, Oreamuno por Oreomuno, Soto Mayor por Sotomayor, siendo en ocasiones la misma familia, los López del Corral en algunas ocasiones aparecen solo por Corral, etc.

En su tesis de licenciatura, la profesora Albarrocín se plantea la siguiente pregunta ¿cuáles fueron los factores que originaron ese proceso de acumulación en la compra y venta de esclavos en el sector dominante de la sociedad cartaginesa? El primer factor a considerar es que existió en Costa Rica al igual que en el resto de Latinoamérica una serie de mecanismos jurídicos e ideológicos que aseguraron la canalización del excedente económico hacia la clase dominante. El engranaje legal de apropiación de la tierra, el control de la mano de obra y de la comercialización destinada a favorecer al grupo hegemónico, se articulaba con el factor ideológico, el cual estaba ligado al papel de la Iglesia que trataba de justificar el orden establecido en beneficio de la clase dominante. Un segundo factor se refiere a las características inherentes

25 Fernando Volio Jiménez, El Apartheid: Prototipo de discriminación racial (San José, Costa Rica: Tesis de Licenciatura en Historia. Universidad de Costa Rica, 1967), 141. 
al grupo hegemónico, el cual mostró una considerable cohesión interna, ya que las familias de Cartago a través de los enlaces matrimoniales establecieron relaciones de parentesco cuyas consecuencias inmediatas fueron favorecer la concentración de capital y asegurar la continuidad del dominio hegemónico de la elite. ${ }^{27}$

Es interesante observar que la elite vieja tradicional tuvo criterios de flexibilidad para ampliarse en su interior, a través de la admisión de inmigrantes extranjeros que fortalecieron su papel. Por otro lado, tenemos que comerciantes de compra y venta de esclavos aparecen como los principales comerciantes de Costa Rica, y ocupando los cargos públicos más importantes. Para citar dos casos: Antonio de la Fuente fue Notario Apostólico, Alférez Real, Regidor, Alcalde Ordinario y Receptor de alcabalas; Tomás López del Corral fue Alguacil Mayor y tuvo también otros cargos públicos, además estos comerciantes formaban parte de la elite económica de la época; por ejemplo, López del Corral fue “propietario “... de dos casas, un conjunto de mulas, varios esclavos y 12,000 árboles de cacao en el Valle de Matina. ${ }^{28}$ El historiador Víctor Hugo Acuña en su tesis de licenciatura dice que el contrato de la Real Renta con López del Corral se dedicó al negocio de la exportación de tabaco y de servir de intermediario entre el producto y la Real Renta y no por ello, dejaron de exportar otros productos y de hacer comercio de importación. ${ }^{29}$

\section{Transacciones en Cartago: 1750-1775}

Este estudio comprende 25 años de 1750 a 1775, fue el despegue y apogeo de los cultivos del cacao y del tabaco en Costa Rica. En estos 25 años se tuvo en Cartago 306 esclavos entre ellos: 69 por ventas, 33 por dotes, 6 donaciones, 6 como hipotecas, 2 por cartas poder y 1 por intercambio. En algunos de los casos de los liberados el esclavo tenía de dos a tres años de tiempo para comprar su libertad; los de testamento se refieren a que eran traspasados como bienes inmuebles. ${ }^{30}$ La edad de los esclavos fue la siguiente:

27 Priscilla Albarrocin González, Estudio histórico demográfico: Algunas familias del Valle Central, 16501850 (San José, Costa Rica: Tesis de Licenciatura en Historia. Universidad de Costa Rica, 1978).

28 ANCR, Protocolos de Cartago. 1750-1775.

29 Víctor Hugo Acuña, Historia económica del tabaco: época colonial (San José, Costa Rica: Tesis de Licenciatura en Historia. Universidad de Costa Rica, 1974), 35. 


$\begin{array}{lc}\text { Años } & \text { Cantidad } \\ 0-10 & 41 \\ 11-21 & 44 \\ 22-32 & 33 \\ 33-43 & 18\end{array}$

44 ó más

Total

Si observamos estos números rápidamente nos percatamos que 85 de los esclavos analizados estaban entre 0 y 21 años, era una población muy joven y que 51 esclavos comprendían las edades de 22 a 43 años. La población esclava de más de 44 era muy poca, esto significa una alta tasa de natalidad o nacimientos y una cantidad de esclavos viejos muy reducida, lo que significa también una alta tasa de mortalidad entre los 44 años o más. Esto no es difícil de comprender si entendemos que las condiciones de salud eran deplorables y sus jornadas de trabajo arduas y extensas. Si sumamos el número de esclavos repartidos por su edad tendríamos que suman 143 de un total de 306. El problema es que en los 163 esclavos restantes no se especificó la edad. ${ }^{31}$ Con respecto al precio promedio de venta de un esclavo estuvo entre los 195 pesos y los 268 pesos de plata. Por ejemplo, entre 1750 y 1754 el precio más alto fue de 235 pesos y el más bajo fue de 125 pesos. De 1755 a 1759 el más alto fue de 275 y el más bajo de 242 pesos. Entre 1760 a 1764 el más alto fue de 228 y el más bajo de 167 pesos. Para 1765 a 1769 el más alto fue de 450 pesos y el más barato fue de 138 pesos. ${ }^{32}$ Finalmente, de 1770 a 1775 el más alto fue de 253 pesos y el más bajo fue de 169 pesos plata. Si observamos los precios suben rápidamente, pero también bajan por lo que es inconsistente el precio promedio bajo y el alto en las diferentes épocas. El año de 1765 fue cuando se pago mejor por un esclavo, pero también fue el inicio de un descenso rápido en el precio promedio de un esclavo que continuó hasta 1775 en que terminó nuestro estudio. La gran mayoría de los esclavos fueron hombres, pero las mujeres eran mejor cotizadas a la hora de ser vendidas ya que sus destrezas y labores en los hogares eran muy valiosas.

El nombre del propietario, como el nombre del comprador aparecen con lujo de detalle en los protocolos, en éstos se específica la profesión u oficio de ambos. Con respecto al nombre del esclavo solo se dice su nombre, generalmente cuando nacían en la casa del propietario no tenían $31 \quad$ ANCR, Protocolos de Cartago. 1750-1775.

32 ANCR, Protocolos de Cartago. 1750-1775. 
su apellido, pero cuando lo compran con apellido dicho esclavo lo mantenía aunque pasara a otro propietario. Su color de piel aparece como un elemento vital para describir al esclavo y así valorizarlo. El tipo de color que más prevaleció en nuestro estudio fue el mulato, le siguió el negro y cuando no se mencionaba su color se denominaba como "esclavo". El hecho de que prevalezca el fenotipo de mulato, significa que el proceso de integración racial en Cartago entre el blanco y el negro se había acelerado más que en algunas otras partes de la República como era en Matina, donde el esclavo por lo general era clasificado como negro. ${ }^{33}$

En la variable referente al tipo de transacción tenemos que algunos esclavos fueron hipotecados (6) casos, el resto fueron vendidos, donados, testados, dote, cartas poder, intercambio, libertad plena y compra. En los 25 años del análisis hecho, sólo aparece un caso donde la libertad fue otorgada por agradecimiento. Luisa de Guzmán le da la libertad a sus siete esclavos en junio de 1772 por agradecimiento por sus servicios. ${ }^{34}$ En la variable referente al mes de la transacción pudimos observar que las ventas y compras de esclavos se realizaron en Cartago durante la época de cosechas de (mayo a diciembre).

Con respecto al precio de un esclavo se decía en qué moneda se podía pagar: pesos plata o en cacao, dicho producto se usó como moneda en Costa Rica durante el siglo XVIII, esto debido a la escasez de numerario; pero siempre la moneda de plata valía un poco más que el cacao. De 1764 hasta 1772, aparecieron gran cantidad de esclavos valorados en cacao y no en pesos de plata.

Otro factor que determinaba el precio considerablemente era si el esclavo era criado o nacido en la casa del amo o no. Después de examinar cuidadosamente los protocolos y mirar el comportamiento en la imposición de un precio a un esclavo, podemos decir que la edad repercutió significativamente en su precio. A menor edad más costoso, a mayor edad menos valioso. Su color parece haber sido otro elemento determinante, si era mulato tenía un valor mayor, debido a que si era negro había sido comprado recientemente, mientras que si era mulato, dicho esclavo había pasado por un proceso de domesticación. Es importante recalcar que en los índices de los protocolos no aparece si los esclavos realizaban tareas domésticas o de campo. En el siglo XVIII Cartago, a pesar de ser la capital de la provincia vivía inmersa en la ruralía, es decir que hacer diferencias tajantes entre labores domésticas y de campo era muy difícil, debido a que un esclavo era muy valioso y había que sacarle el mayor provecho posible. 33 ANCR, Protocolos de Cartago. 1750-1775.

34 ANCR, Protocolos de Cartago. Número 960, Legajo VII, Exp. 22. 
Creemos que el esclavo, tanto mujer como varón colaboraba en la siembra y la recolección de la cosecha y también en las labores de la casa como sirvientes en épocas sin cosechas.

Las investigaciones de Monseñor Thiel y comparando los nombres de los curas de la ciudad de Cartago, vicarios y jueces eclesiásticos, nombrados de 1750-1775 tenemos que participaron activamente en la compra y venta de esclavos. Entre dichos clérigos estaban: José M. Guzmán y Chavarría (1750-1767), Juan Francisco Ibarra (1767-1769), Juan Francisco Alvarado (17701776), Juan Manuel Casasola (1753-1759), Juan José Camacho (1750), Antonio de Guevara y Sáenz (1750), Obispo Mateo José de Nava (1760), José M. García de Echevarria (1765), José H. de Arlegui (1769), Juan de la Haya (1769), Juan López del Corral (1772). Los primeros cuatro curas residían permanentemente en Cartago, se desconoce la residencia del resto de los clérigos. ${ }^{35}$

\section{Conclusiones}

Amanera de conclusión tenemos que la esclavitud negra en Costa Rica fue una realidad histórica. El esclavo como en el resto de América sufrió en carne propia el mal trato, desintegración familiar y explotación sin medida. Realmente aseverar que de los 306 esclavos cierta cantidad se dedicaban a oficios domésticos y otra cantidad a labores de campo es imposible porque carecemos de evidencia suficiente. Solamente cuando se les otorgaba la libertad condicionada por su propia compra sabemos que trabajaba en el campo, pues era el medio que utilizaban para pagar su libertad.

En algunos testamentos encontramos que algunos esclavos eran hijos del esclavista y en su lecho de muerte los reconocían ante el notario y su familia. Algunos les daban el apellido, pero la gran mayoría seguía con el nombre de nacimiento. Decir que no hubo división social en el País no es cierto. De lo contrario, no habría riqueza acumulada para invertir en la producción de cacao, tabaco, minas y posteriormente en el café durante el siglo XIX.

En todos los 306 casos que consulté no encontré indicios de que los esclavos fueran vendidos por maltrato, pero casi todas las cartas de poder que aparecían en los protocolos eran para vender esclavos localizados en Nicaragua que habían huido de Costa Rica y es probable que la razón de haber huido fuera por maltrato. En cuanto a la cantidad de esclavos con relación a su precio y número de propietarios tenemos que eran considerados como piezas valiosas que tenían precios entre 200 y 400 pesos por cada esclavo. El número de propietarios era de 
158, de los privilegiados gran parte eran individuos corrientes; pero también encontramos funcionarios reales, sacerdotes, militares y otros. La libertad a los esclavos y esclavas viejas se les fue daba no por humanidad del esclavista sino porque resultaba mejor darle su libertad condicionada, que mantenerlo. Esta investigación es una pequeña contribución a la historia de la esclavitud en Costa Rica. Nos queda un largo camino por recorrer en los Archivos de Costa Rica, Guatemala, Sevilla y Londres.

\section{Bibliografía}

\section{Fuentes Secundarias}

Acuña Ortega, Víctor H. Historia económica del tabaco: época colonial. Tesis de Licenciatura en Historia, Universidad de Costa Rica, 1974.

Aguilar Bulgarelli, Oscar. La esclavitud en Costa Rica durante el período colonial. San José, Costa Rica, Universidad de Costa Rica, 1973.

Albarrocín González, Priscilla. Estudio histórico-demográfico: algunas familias del Valle Central: 1650-1850. San Jose, Tesis de Licenciatura en historia, Universidad de Costa Rica, 1978.

Alvarado Roses, Carlos. El cacao en la economía colonial. San Jose, Tesis de Licenciatura en Historia, Universidad de Costa Rica, 1975.

Brenes Castillo, M. Matina: bastión del contrabando en Costa Rica. Tesis de Licenciatura en Historia, Universidad de Costa Rica, 1976.

Jiménez Castro, WiIburg. Migraciones internas en Costa Rica. Washington, D.C., Unión Panamericana, 1956.

Meléndez, Carlos y Quince Duncan. El neqro en Costa Rica. San José, Costa Rica. Editorial Costa Rica, 1972. 
Monge Alfaro, Carlos. Historia de Costa Rica. San Jose, Imprenta Trejos, 1966.

Solórzano Fonseca, Juan Carlos. Comercio exterior de la provincia de Costa Rica: 1690-1760. San José. Tesis de Licenciatura en Historia, Universidad de Costa Rica, 1977.

Thiel, Bernardo. "La población de Costa Rica en el siglo XIX”. Revista de Costa Rica en el siglo XIX. San Jose, Tipografía Nacional, tomo I, 1902.

Volio Jiménez, Fernando. El apartheid: prototipo de discriminación racial. San Jose, Tesis de Licenciatura en Historia, Universidad de Costa Rica, 1967. 
Indexaciones: Repositorio de Revistas UCR, DIALNET, Latindex, REDALYC Directorio y recolector de recursos digitales del Ministerio de Cultura de España, Directory of Open Access Journals.

Diálogos Revista Electrónica de Historia ISSN 1409- 469X. Número especial 2008. Dirección web: http://historia.fcs.ucr.ac.cr/dialogos.htm

Fuentes Primarias

Archivo Nacional de Costa Rica (ANCR)

ANCR, Protocolos de Cartago:

$\begin{array}{llll}\text { Año } & \text { Número } & \text { Legajo } & \text { Expediente } \\ 1750 & 940 & \text { VII } & 1 \\ 1751 & 941 & \text { VII } & 2 \\ 1752 & 942 & \text { VII } & 4 \\ 1753 & 943 & \text { VII } & 5 \\ 1754 & 944 & \text { VII } & 5 \\ 1755 & 944 & \text { VII } & 6 \\ 1756 & 945 & \text { VII } & 6 \\ 1757 & 946 & \text { VII } & 8 \\ 1758 & 947 & \text { VII } & 9 \\ 1759 & 948 & \text { VII } & 10 \\ 1760 & 948 & \text { VII } & 10 \\ 1761 & 949 & \text { VII } & 11 \\ 1762 & \text { VII } & 12 \\ 1763 & 950 & \text { VII } & 13 \\ 1764 & 951 & \text { VII } & 14 \\ 1765 & \text { VII } & 15 \\ 1766 & 952 & \text { VII } & 16 \\ 1767 & 953 & \text { VII } & 17 \\ 1768 & 954 & \text { VII } & 18 \\ 1769 & 955 & \text { VII } & 19 \\ 1770 & 956 & \text { VII } & 20 \\ 1771 & 957 & \text { VII } & 21 \\ 1772 & 958 & \text { VII } & 22 \\ 1773 & 959 & \text { VII } & 23 \\ 1774 & 960 & \text { VII } & 1 \\ 1775 & 961-962 & \text { VII } & 2\end{array}$

